\title{
Avaliação comparativa de dosagem do marcador tumoral CA 15-3 em cadelas hígidas ou com neoplasia mamária ${ }^{1}$
}

\author{
Gabriela B. Roberto ${ }^{2,3 *}$, Liane Ziliotto² e Meire Christina Seki ${ }^{2}$
}

\begin{abstract}
Roberto G.B., Ziliotto L. \& Seki M.C. 2018 [Comparative evaluation of tumor marker CA 15-3 dosage in dogs, healthy or with breast cancer.] Avaliação comparativa de dosagem do marcado tumoral CA 15-3 em cadelas hígidas ou com neoplasia mamária. Pesquisa Veterinária Brasileira 38(9):1800-1807. Programa de Pós-Graduação em Ciências Veterinárias, Universidade Estadual do Centro-Oeste, Rua Semeão Camargo Varela de Sá 3, Vila Bela, Guarapuava, PR 85040-080, Brazil. E-mail: gabi_basilio1988@hotmail.com

The CA 15-3 antigen is a protein present in the serum, used to monitor women with breast cancer, mainly in metastatic disease detection. The objective of this study was to evaluate the effectiveness and feasibility of the CA 15-3 tumor marker in dogs, comparing the marker values between dogs with or without breast cancer, to estimate changes in marker values after mastectomy, and their correlation between the histological types. Serum quantification of the tumor marker CA 15-3 (electrochemiluminescence test) was performed in twenty healthy bitches and twenty others with mammary neoplasia. Bitches with cancer had the content of the tracer performed before and 10 days after mastectomy. The vaginal cytology was performed at the moment of the mastectomy, dividing the animals into three different groups (diestrus, proestrus and anestrus). All the mammary tumors were examined histopathologically. The evaluation of the vaginal cytology data of the groups Diestro, Proestro and Anestro by the ANOVA test did not show a statistically significant difference between the values found. In the analysis histological types of tumor marker values of neoplasms, divided into two groups, benign and malignant, using the Mann-Whitney Rank Sum Test, there was no statistical significant difference at $p>0.05$. The values of the marker in the control group had an average of $0.19+0.39 \mathrm{U} / \mathrm{mL}$, of the pre-mastectomy group $1.56+0.39 \mathrm{U} / \mathrm{mL}$, and of the post-mastectomy group $0.66+0.27 \mathrm{U} / \mathrm{mL}$. The statistic was performed comparing groups pre- and post-mastectomy, and the control group with group pre- and post-mastectomy with a statistical significance $p<0.005$ in both tests. There was a difference of marker values before and after surgical removal of the neoplasia, suggesting its possible use in post-mastectomy tumor control. But exist variation of results with the different existing methods, and there will be still a standard reference value for each method.
\end{abstract}

INDEX TERMS: Bitches, caninos, breast cancer, tumor marker CA 15-3, electrochemiluminescence, prognosis, mastectomy, pathology.

RESUMO.- 0 antígeno CA 15-3 é uma proteína presente no soro utilizado no acompanhamento de mulheres com câncer de mama, essencialmente na detecção de metástases. Os objetivos

\footnotetext{
${ }^{1}$ Recebido em 2 de outubro de 2017.

Aceito para publicação em 2 de novembro de 2017.

${ }^{2}$ Pós-Graduação em Ciências Veterinárias, Universidade Estadual do Centro-Oeste (Unicentro), Rua Simeão Camargo Varela de Sá 3, Vila Bela, Guarapuava, PR 85040-080, Brasil. *Autor para correspondência: gabi_basilio1988@hotmail.com

${ }^{3}$ Departamento de Medicina Veterinária, Universidade Estadual do Centro-Oeste (Unicentro), Rua Simeão Camargo Varela de Sá 3, Vila Bela, Guarapuava, PR 85040-340.
}

deste estudo foram avaliar a efetividade e a viabilidade da utilização do marcador tumoral CA 15-3 em cadelas, comparando-se os valores do marcador entre cadelas sem e com neoplasia mamária, avaliando-se alterações nos valores do marcador após a mastectomia, e suas correlações entre o tipo histológico. Foi realizada a quantificação sérica do marcador tumoral CA 15-3 (teste de eletroquimioluminescência), em vinte cadelas hígidas (grupo controle) e vinte cadelas com neoplasia mamária (grupo teste). Os animais com neoplasia tiveram a dosagem do marcador realizada antes e 10 dias após a mastectomia. Ainda, foi realiza a citologia vaginal no momento da mastectomia e foram estabelecidos três grupos 
de acordo com a fase estral de cada cadela, Diestro, Proestro e Anestro. As massas tumorais foram encaminhadas para exame histopatológico. A avaliação dos dados de citologia vaginal entre os grupos Diestro, Proestro e Anestro pelo teste de ANOVA não demonstrou diferença estatística significativa entre os valores encontrados. E na análise para a comparação dos valores do marcador tumoral com os tipos histológicos de neoplasias, divididas em dois grupos, benignas e malignas, utilizando o teste de Mann-Whitney Rank Sum Test, o teste não demonstrou diferença estatística significativa visto que $p>0,05$. Os valores encontrados do marcador no grupo controle foram uma média de $0,19+0,39 \mathrm{U} / \mathrm{mL}$, no grupo pré-mastectomia 1,56+0,39 U/mL e pós-mastectomia 0,66+0,27 U/mL. Em análise estatística com a comparação de grupo pré e pós-mastectomia, e do grupo controle com o grupo pré e pós-mastectomia observou-se significância com $\mathrm{p}<0,005$. Assim, observou-se diferença nos valores do marcador antes e depois da remoção cirúrgica da neoplasia, sugerindo seu possível uso como controle de crescimento tumoral pós-mastectomia individual. Porém há muita variação dos resultados nos diferentes métodos existentes, e não há ainda um padrão dos valores de referência para cada método, sendo necessários mais estudos sobre o uso dos marcadores.

TERMOS DE INDEXAÇÃO: Cadela, caninos, cancêr de mama, marcador tumoral CA 15-3, eletroquimioluminescência, prognóstico, mastectomia, patologia.

\section{INTRODUÇÃO}

Define-se neoplasia como o crescimento celular em que ocorre alteração permanente e hereditária nas células de maneira errônea. A proliferação celular anormal excessiva, intencional e não autônoma, que continua indefinidamente devido os efeitos da neoplasia em crescimento gera o tumor (Rodaski \& Piekars 2009, Bicalho 2012).

As neoplasias mamárias são muito comuns em cadelas, alcançando de $50 \%$ a $70 \%$ de todos os tumores que acometem uma população (Lana et al. 2007, Cassali et al. 2014). Além da sua importância em medicina veterinária é ainda muito investigada, principalmente por servir de modelo para o estudo do câncer de mama na mulher (Garrido 2011, Feliciano et al. 2012).

Quanto ao tipo histológico, aproximadamente 35\% a 50\% das neoplasias mamárias caninas são malignas (Oliveira et al. 2003, Withrow \& Macewen 2007, Cirilo 2008, Fossum et al. 2008).

Sua ocorrência varia conforme a característica da população, como o hábito de realizar a ovariosalpingohisterectomia em cadelas jovens, a idade e a raça dos cães (Lana et al. 2007). No Brasil, Daleck et al. (1998), afirmam que os tumores de mama acometem cães de idade média a avançada, sem predisposição de raça ou idade.

0 efeito hormonal para o desenvolvimento da neoplasia mamária pode ser avaliado pela incidência do desenvolvimento tumoral e sua relação com a fase hormonal em que as fêmeas são submetidas à ovariohisterectomia (Bicalho 2012, Feliciano et al. 2012). A castração antes do primeiro estro reduz o risco de neoplasia mamária a menos de 0,5\% (Lana et al. 2007, Fossum et al. 2008). Este risco aumenta para $8 \%$ após o primeiro ciclo estral e para $26 \%$ após o segund o cio (Fonseca \& Daleck 2000, Oliveira et al. 2003, Fossum et al. 2008).
Porém, a maioria dos estudos não mostra efeito protetor da OSH realizada após os quatro anos de idade (Lana et al. 2007).

A influência hormonal descrita pode ser avaliada pelo fato de muitos estudos terem comprovado a presença de receptores de estrogénio (ER), progesterona (PR), prolactina (PRL-R), e fatores de crescimento epidérmico (EGF-R) nas glândulas mamárias normais ou em portadores de tumores mamários benignos e malignos (Misdorp 2002). Comprovou-se, ainda, que a exposição a doses farmacológicas de hormônios exógenos é capaz de aumentar o risco de desenvolvimento de tumores mamários em cães, tornando-o 2,3 vezes maior (Misdorp 2002, Lana et al. 2007).

Apesar dos nódulos mamários serem facilmente identificados ao exame físico, este deve ser minucioso já que os nódulos malignos podem gerar metástases para vários órgãos, sendo os linfonodos regionais e os pulmões os mais comumente afetados (Daleck et al. 1998). A avaliação de metástases distantes, principalmente pulmonares, deve ser realizada sempre nos pacientes com neoplasia mamária antes da indicação cirúrgica (Cassali et al. 2014). 0 diagnóstico definitivo do tipo de tumor é possível por meio de microscopia, por citologia ou histopatologia. A avaliação histopatológica pode ser realizada por meio de biopsias ou excisões da neoplasia em sua totalidade (Misdorp 2002, Sakamoto 2011). Mais recentemente a imuno-histoquímica tem revolucionado o diagnóstico na oncologia, pois, além do auxílio ao diagnóstico de vários tipos de neoplasia, a imuno-histoquímica tem permitido a identificação de diferentes tipos de marcadores (enzimas, receptores, outros produtos de genes, etc.) que estão relacionados ao comportamento biológico das neoplasias tanto em mulheres como em cadelas (Zuccari et al. 2009).

A remoção cirúrgica (mastectomia) é a primeira linha de tratamento para o tumor de mama em cadelas, exceto no carcinoma inflamatório (Cassali et al. 2014). 0 tipo do tumor, o estágio da doença e os sinais sistêmicos devem ser averiguados, para se definir se a paciente está apta ou não para o tratamento cirúrgico (Lana et al. 2007).

Os marcadores tumorais podem ser componentes estruturais, bioquímicos e celulares presentes tanto em células tumorais como normais (Capelozzi 2001). São em sua maioria proteínas ou pedaços de proteínas, presentes no tumor, no sangue ou em outros líquidos biológicos. A formação e o crescimento de células neoplásicas levam ao aparecimento e ou alterações em suas concentrações (Souza 2002, Mattos et al. 2005, Almeida et al. 2007). Essas macromoléculas podem ser formadas pela neoplasia, ou podem ser referentes à resposta no organismo à presença no tumor (Araújo 2013) e podem ser quantificados ou detectados por testes bioquímicos ou imunohistoquímicos (Mattos et al. 2005). A avaliação dos marcadores tumorais para definição de prognóstico do câncer de mama tem avançado significativamente nos últimos anos (Eisenberg \& Koifman 2001).

Os marcadores mucinosos e de tipo mucinosos mais estudados hoje são: CA 125, CA 15-3, CEA (carcinoembrionário) e CA 19-9 (Souza 2002). A mucina (MUC 1), é um complexo glicoprotéico gigante que localiza-se extracelularmente. Nas células malignas, a presença da mucina está elevada, e sua dosagem no sangue pode indicar a ocorrência de neoplasias, e determinar a presença de doença redicivante, progressão ou resposta à terapia (Souza 2002, Manuali et al. 2012). 
0 antígeno CA 15-3 tem sido utilizado no acompanhamento de mulheres com câncer de mama, principalmente na detecção de metástases, antes mesmo do surgimento de manifestações clínicas, sendo o mais sensível atualmente (Geraghty et al. 1992, Bicalho 2012, Lopez et al. 2012).

0 aumento superior a $25 \%$ na concentração desse marcador está relacionado a evolução da doença em até $90 \%$ dos casos, em contrapartida, uma redução na concentração está associada à regressão em até $80 \%$ dos casos (Almeida 2006). Silveira (2005) relatou ainda que níveis muito elevados desse marcador estão associados à pior prognóstico e sobrevida reduzida.

Baseados nestes conhecimentos, Almeida et al. (2007) recomendaram que a dosagem do CA 15-3 fosse efetuada antes do tratamento, após 2 a 4 semanas do tratamento (cirúrgico ou quimioterápico) e um acompanhamento a cada 3 a 6 meses.

Em medicina veterinária Marchesi et al. (2010), realizaram um trabalho de avaliação da concentração sérica e plasmática do CA 15-3 em cães, com o objetivo de determinar um valor de referência para a espécie. 0 estudo avaliou o marcador sérico em grupos de cadelas saudáveis e cadelas com diferentes lesões neoplásicas. Porém, devido à diversidade dos tipos tumorais e a não especificidade para o câncer de mama, não foi possível estabelecer um parâmetro de comparação para o marcador em cadelas portadoras de carcinoma mamário. Já Manuali et al. (2012), constataram em seu experimento que os níveis séricos do CA 15-3 tiveram correlação significativa com o grau de malignidade histológico do tumor de mama em cadelas.

0 marcador ideal reúne as características de monitorização da resposta terapêutica e detecção precoce de recidiva, além de diagnóstico precoce de neoplasias e de sua origem, e estabelecimento da extensão da doença. Esse marcador ainda não existe, e alguns apresentam falta de especificidade e sensibilidade. Desta forma, ele deve ser avaliado associando-se com a clínica ou demais exames do paciente (Almeida et al. 2007, Oliveira \& Fonseca 2011).

Os objetivos do presente trabalho foram avaliar a efetividade e a viabilidade da utilização do marcador tumoral CA 15-3 para definição de diagnóstico/prognóstico em cadelas com neoplasias mamárias, buscando assim novos meios para o diagnóstico precoce e seguimento. Também se buscou a análise de parâmetros do marcador em cadelas sem neoplasias mamárias, comparando os valores do marcador entre cadelas sem e com neoplasia mamária, além da avaliação das alterações nos valores do marcador pré e pós a remoção da neoplasia mamária (mastectomia), comparação e correlações entre o tipo histológico, as características do tumor e os valores obtidos no marcador.

\section{MATERIAL E MÉTODOS}

Este estudo fez a quantificação sérica do marcador tumoral CA 15-3 em vinte cadelas hígidas e 20 cadelas com neoplasia mamária. Os animais utilizados foram provenientes da rotina da Clínica Escola Veterinária (CEVET) da Universidade Estadual do Centro-Oeste (Unicentro).

Seleção dos animais. As cadelas foram divididos em 2 grupos. No primeiro (grupo controle) foram utilizadas 20 cadelas castradas antes do primeiro estro (sem exposição de estrógeno em tecido mamário). No segundo grupo (grupo teste) foram utilizadas 20 cadelas apresentando neoplasia mamária.

As cadelas com neoplasia mamária, atendidas na Clínica Escola Veterinária da Unicentro, passaram por avaliação clínica e foram encaminhadas para o setor de cirurgia, onde foram realizados os exames pré-operatórios como exames radiográficos para pesquisa de metástases, hemograma e exames bioquímicos renal (creatinina) e hepático (alanina aminotrasferase - ALT). As cadelas que apresentaram alguma alteração nesses exames, como infeções uterinas, alterações renais ou hepáticas, ou apresentavam alguma outra alteração compatível com outro tipo de neoplasia, não fizeram parte do projeto. Os animais selecionados como aptos, fizeram parte do grupo teste deste trabalho e foram então encaminhados para o serviço de cirurgia onde se definiu o tratamento cirúrgico mais adequado.

Técnica cirúrgica e protocolo anestésico. 0 protocolo anestésico utilizado foi com medicação pré-anestésica, seguida de indução e manutenção anestésicas. Os fármacos utilizados na medicação pré-anestésica foram metadona ou morfina, associadas ou não com clorpromazina ou midazolam; para indução anestésica foi utilizado propofol e para manutenção o isoflurano.

As técnicas cirúrgicas realizadas nas cadelas do grupo teste foram adotadas de acordo com as mamas envolvidas e as características clínicas de cada paciente, sendo realizadas nos animais participantes deste trabalho a mastectomia total unilateral ou a mastectomia regional.

Análise de ficha clínica. 0 levantamento de dados do trabalho também foi realizado através da avaliação da ficha clínica dos pacientes que participaram do projeto. Dados como utilização de progestágeno, presença de ulceração na neoplasia, quais mamas estavam acometidas pelos nódulos, idade e raça dos animais foram extraídos da anamnese e exame físico realizados pelo clínico que atendeu cada paciente.

Exame histopatológico. Após a cirurgia, as mamas removidas com os nódulos ou massas tumorais foram acondicionadas em formol $10 \%$ pelo período de 48 horas, e depois eram realocados em álcool a 70\% para sua conservação e posterior envio para a realização de exame histopatológico. 0 material foi enviado para o Laboratório VetPat ${ }^{\circledR}$ para realização desses exames, através da coloração de HE (Hematoxilina-Eosina).

Citologia vaginal. Foram realizados esfregaços vaginais para a execução de citologia vaginal no grupo teste. A coleta foi feita no momento da cirurgia, após a indução anestésica, onde foram confeccionadas duas lâminas através de swab vaginal, para posterior leitura, e foram estabelecidos três grupos de acordo com a fase estral de cada cadela: Diestro, Proestro e Anestro. As lâminas foram encaminhadas para o Laboratório de Doenças Infecciosas e Parasitárias da Universidade Estadual do Centro-Oeste (Unicentro). As amostras submetidas à avaliação citoscópica foram coradas pelo Panótico - Instant-Prov ${ }^{\circledR}$. A citologia vaginal objetivou determinar o momento do ciclo estral das cadelas operadas e definir uma possível interferência hormonal nos resultados.

Análise do marcador tumoral. Para a análise do marcador tumoral CA 15-3 foi realizada a coleta de sangue em apenas um momento nas cadelas do grupo controle e em dois momentos nos animais do grupo teste. As coletas foram de $3 \mathrm{~mL}$ de sangue, através de venopunção da jugular, e as amostras foram acondicionadas em tubos sem anticoagulante para a realização da dosagem do marcador tumoral CA 15-3. Nos indivíduos do grupo controle a coleta foi realizada no momento do primeiro atendimento após o exame físico geral detalhado para se descartar a presença de qualquer doença ou condição que pudesse interferir no resultado do exame.

Nas cadelas do grupo teste a primeira coleta foi realizada imediatamente após a indução anestésica (e, portanto antes do início do procedimento cirúrgico) e a segunda coleta de sangue para dosagem do marcador foi realizada 10 dias após a mastectomia, no momento em que os animais retornavam a clínica escola para retirada dos pontos. Para o marcador tumoral, o soro foi encaminhado para o Laboratório 
Biolabor $^{\circledR}$ em Itararé - SP. 0 método utilizado pelo laboratório foi a eletroquimioluminescência através do kit Elecsys CA 15-3 II ${ }^{\circledR}$.

Análise estatística. Os dados foram tabulados e analisados por programa computacional Sigma Stat for Windows (2009), aplicando-se o teste t pareado (médias) para comparar o grupo pré-mastectomia com o grupo pós-mastectomia. Para análise estatística realizada entre os grupos controle e pré-mastectomia e grupo controle e pós-mastectomia não foi possível utilizar o teste $t$, sendo então utilizado o teste de Mann-Whitney Rank Sum (medianas), por se tratarem de grupos de diferentes animais e os dados não apresentaram distribuição normal. Para análise na citologia vaginal o teste utilizado foi o One Way Analysis of Variance (ANOVA) para comparação dos grupos anestro, proestro e diestro. Já para a análise entre os dois grupos de tumores benignos e malignos o teste estatístico utilizado foi Mann-Whitney Rank Sum Test.

\section{RESULTADOS}

Durante os atendimentos e avaliações para seleção dos pacientes do grupo teste, com neoplasia mamária, as mais diferentes apresentações clínicas foram observadas, como tumores de tamanhos variáveis, com o menor medindo $0,5 \mathrm{~cm}$ e o maior mais de $11 \mathrm{~cm}$ de comprimento. Também foi observada a presença de ulcerações em tumores e uma maior prevalência de neoplasias nas mamas inguinais em comparação as outras mamas.
A escolha dos procedimentos cirúrgicos variou conforme a apresentação clínica dos tumores, e com o estado geral das pacientes submetidas ao procedimento. A maioria das cadelas foi submetida à mastectomia total unilateral, por estarem aptas a passar por esse procedimento, e por esta ser a técnica de escolha na Clínica Escola. Na Figura 1 podem ser observadas algumas das características tumorais encontradas.

Nos exames pré-operatórios nenhum animal apresentou alteração em imagem radiográfica compatível com metástase, e os exames hematológicos e bioquímicos apresentaram-se dentro dos valores de normalidade, sendo que $45 \%$ dos pacientes, todos do grupo teste (Cadelas 2, 4, 5, 6, 7, 8, 9, 12 e 18) apresentaram leucocitose por neutrofilia.

Sobre a utilização de progestágenos nas cadelas que participaram do projeto, seis animais (30\%) utilizaram uma ou mais doses de progestágeno durante a vida, 11 (55\%) não utilizaram, e em três (15\%) os proprietários não souberam informar.

A média de idade de pacientes acometidos com neoplasias mamárias durante a pesquisa foi de 9,85 $(+2,3)$ anos. Por esse motivo o protocolo anestésico mais utilizado foi aquele considerado mais seguro para a maioria das cadelas: (1) Medicação pré-anestésica (MPA): metadona com midazolan; (2) Indução: propofol; 3 Manutenção: isoflurano. Sendo que devido a algumas alterações clínicas ou comportamentais de alguns pacientes a MPA sofreu algumas alterações como adição de
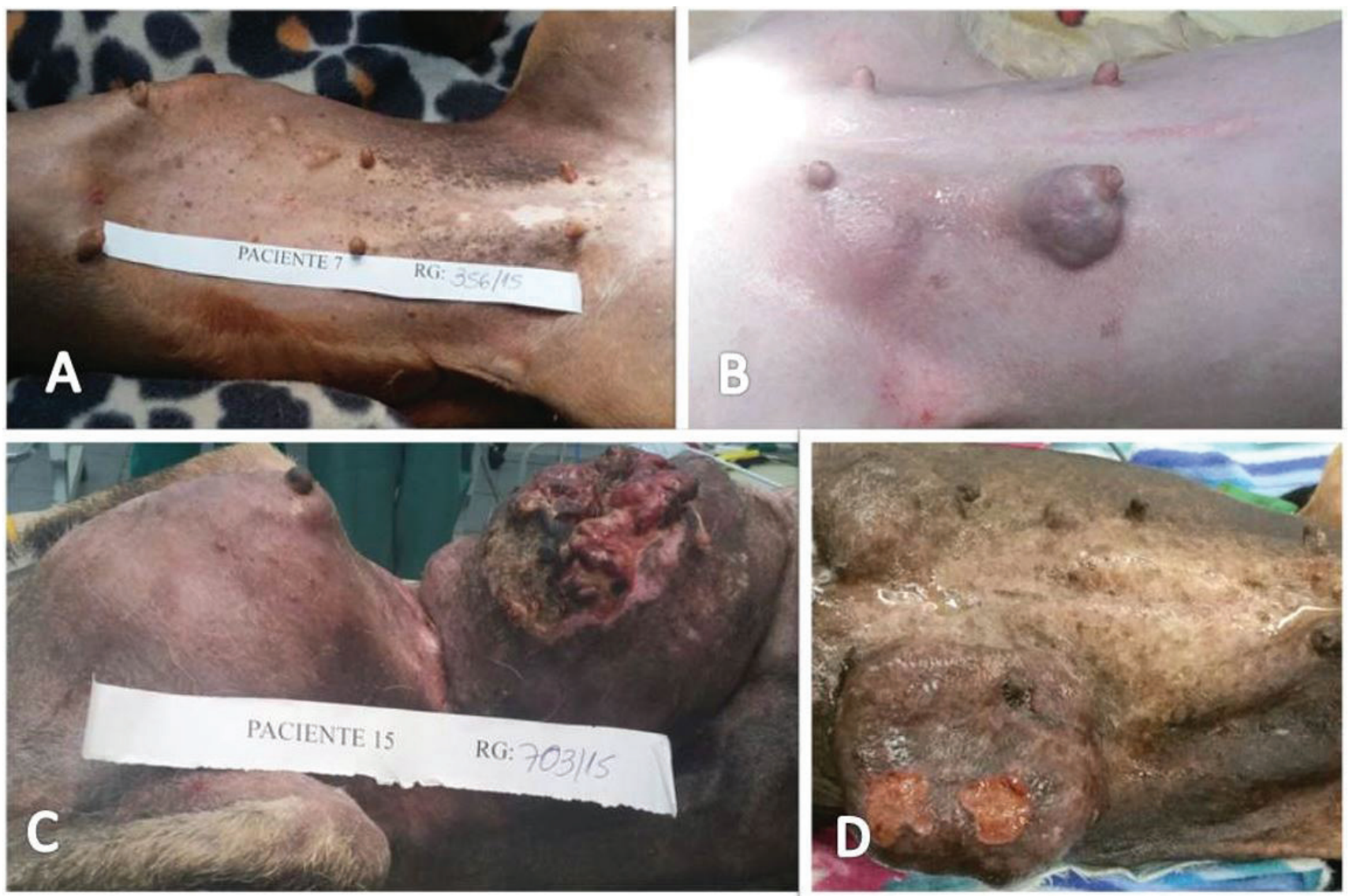

Fig.1. Quatro cadelas que participaram do projeto (grupo teste), demonstrando a variedade de apresentação clínica das neoplasias. $(\mathbf{A}, \mathbf{B})$ Nódulos pequenos, sem ulceração em apenas uma mama. (C,D) Estágio mais avançado da doença, com neoplasias grandes o ulceradas acometendo mais de uma mama. 
clorpromazina (Cadelas 7 e 15), devido ao comportamento agitado, e a utilização apenas de metadona (Cadelas 3, 4, 5, 7) por apresentarem-se mais debilitados.

Referente à raça de maior casuística no grupo teste da pesquisa, SRD (sem raça definida) correspondeu a 15 animais (80\%), os outros $20 \%$ foram compostos de um Border Collie (5\%), um Pinscher (5\%), um (5\%) Dachshund e um (5\%) Cocker.

Das 20 cadelas do grupo teste, um animal (5\%) apresentou neoplasia em $M_{1}$, oito cadelas (40\%) em $M_{2}, 12$ cadelas ( $\left.60 \%\right)$ em $M_{3}, 13$ cadelas (65\%) em $M_{4}$ e oito cadelas (40\%) em $M_{5}$. Um mesmo animal apresentou neoplasia em mais de uma mama. As glândulas mamárias mais acometidas foram $M_{3}, M_{4}$ e $M_{5}$

Referente aos exames histopatológicos realizados após a mastectomia, dos 20 animais pesquisados, tivemos três (15\%) que apresentaram neoplasias benignas e 17 (85\%) que apresentaram neoplasias malignas. Como alguns animais apresentavam mais que um nódulo ou massa mamária, o total de lesões encaminhadas para exame histopatológico foi de 44 nódulos ou massas. Sendo que desses, quatro (10\%) foram benignos, onde os quatro foram classificados como tumor mamário misto benigno. Os outros 40 (90\%) foram malignos, onde tivemos desses 40 , um caso $(2,5 \%)$ classificado como carcinossarcoma mamário e os outros $39(97,5 \%)$ como carcinoma, desses os tipos prevalecentes foram, sólido, papilífero e misto, dos mais variados graus.
Quanto a citologia vaginal foram observados 12 cadelas $(60 \%)$ em anestro, três cadelas (15\%) em proestro e duas cadelas (10\%) em estro, não foi possível a identificação do ciclo estral em três animais (15\%), devido a contaminação da amostra, ou coleta de material inadequada.

Na análise do marcador tumoral CA 15-3 pode-se observar, no grupo teste, que os valores obtidos na análise das amostras variaram entre 1 e 2,4 U/mL nas amostras pré-mastectomia, entre 0,09 e $0,9 \mathrm{U} / \mathrm{mL}$ nas pós-mastectomia e valores entre 0,09 e $0,7 \mathrm{U} / \mathrm{mL}$ no grupo controle (Quadro 1).

Na Figura 2 observa-se um gráfico com os valores do marcador tumoral CA 15-3 obtidos pelo grupo teste (pré e pós-mastectomia) e pelo grupo controle.

No Quadro 1 observam-se os dados obtidos na análise estatística de média, erro padrão e mediana, onde os valores de média encontrados do marcador tumoral no grupo controle foram de 0,19+0,39 $\mathrm{U} / \mathrm{mL}$, no grupo pré-mastectomia de $1,56+0,39 \mathrm{U} / \mathrm{mL}$ e no grupo pós-mastectomia de $0,66 \pm 0,27 \mathrm{U} / \mathrm{mL}$. A análise estatística entre os grupos pré-mastectomia e controle, utilizando Mann-Whitney Rank Sum, apontou diferença significativa entre os dois grupos $(p<0,05)$. Diferença significativa $(p<0,05)$ também foi encontrada entre o grupo controle e o grupo pós-mastectomia, de acordo com o mesmo teste. De acordo com o teste t, a concentração do marcador

\section{Quadro 1. Valores séricos individuais numéricos de CA 15-3 de cada grupo de cadelas encontrados no experimento e valores da média + desvio padrão, mediana e erro padrão encontrados no experimento, através do método de eletroquimioluminescência}

\begin{tabular}{|c|c|c|c|c|}
\hline \multirow{2}{*}{ Cadela teste } & \multicolumn{4}{|c|}{ Marcador tumoral CA 15-3 (em U/mL) } \\
\hline & Pré mastectomia & Pós-mastectomia & Cadela controle & Controle \\
\hline 1 & 1 & 0,9 & 1 & 0,09 \\
\hline 2 & 1,8 & 0,7 & 2 & 0,6 \\
\hline 4 & 1,3 & 0,6 & 4 & 0,4 \\
\hline 5 & 1,5 & 0,4 & 5 & 0,4 \\
\hline 8 & 2,2 & 0,9 & 8 & 0,09 \\
\hline 9 & 1,4 & 0,9 & 9 & 0,09 \\
\hline 10 & 1,8 & 0,9 & 10 & 0,1 \\
\hline 11 & 1,8 & 0,8 & 11 & 0,09 \\
\hline 12 & 1,4 & 0,8 & 12 & 0,09 \\
\hline 16 & 2 & 0,8 & 16 & 0,1 \\
\hline 17 & 1,5 & 0,7 & 17 & 0,1 \\
\hline 18 & 1,3 & 0,09 & 18 & 0,4 \\
\hline 19 & 2,4 & 0,2 & 19 & 0,09 \\
\hline 20 & 1,9 & 0,09 & 20 & 0,09 \\
\hline Média & $1,56+0,39^{a}$ & $0,66+0,27^{b}$ & - & $0,19+0,39$ \\
\hline Mediana & $1,45^{\mathrm{B}}$ & $0,7^{\mathrm{C}}$ & - & $0,095^{\mathrm{A}}$ \\
\hline Erro Padrão & 0,09 & 0,06 & - & 0,04 \\
\hline
\end{tabular}

\footnotetext{
${ }^{\text {a,b }}$ Médias com diferenças estatísticas significativas entre grupos (pré- e pós-mastectomia) com as mesmas cadelas. Teste t pareado ( $\mathrm{n}=20$ ). ${ }^{\mathrm{A}, \mathrm{B}}$ Medianas com diferenças estatísticas significativas entre grupos (pré-mastectomia e controle). Teste Mann-Whitney Rank Sum (n=20). ${ }^{\mathrm{A}, \mathrm{C}}$ Medianas com diferenças estatísticas entre grupos (pós-mastectomia e controle) Teste Mann-Whitney Rank Sum (n=20).
} 


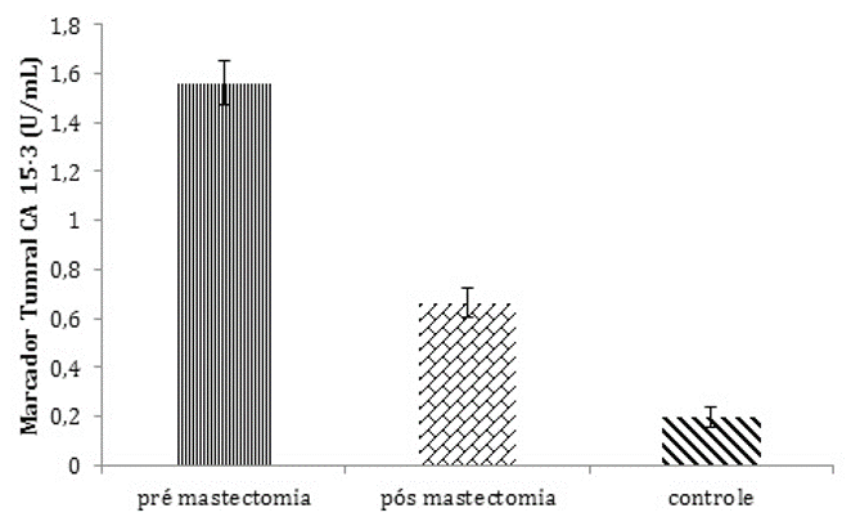

Fig.2. Valores do marcador CA 15-3 representados em média e erro padrão do grupo teste pré e pós-mastectomia $(\mathrm{n}=20)$ e do grupo controle $(n=20)$, encontrados no experimento, através do método de eletroquimioluminescência.

tumoral CA 15-3 entre os grupos pré e pós-mastectomia foi significativamente diferente $(\mathrm{p}<0,05)$.

A avaliação das concentrações séricas do marcador mensurado nos grupos Diestro, Proestro e Anestro, divididos através da citologia vaginal pelo teste de ANOVA, não demonstrou diferença estatística. E na análise para a comparação dos valores do marcador tumoral com os tipos histológicos de neoplasias, divididas em dois grupos, benignas e malignas, utilizando o teste de Mann-Whitney Rank Sum Test, o teste não demonstrou diferença estatística significativa visto que p>0,05.

\section{DISCUSSÃO}

A realização desse trabalho justifica-se devido a carência de estudos sobre os marcadores tumorais em cadelas, e a alta incidência desta neoplasia nessa espécie (De Nardi et al. 2002, Bicalho 2012).

As características clínicas encontradas durante a realização do experimento foram que as cadelas atendidas apresentavam média de idade de 9,85 $(+2,3)$ anos, muito próximo a pesquisa de Oliveira et al. (2003) que encontraram média de idade de $9(+3,1)$ anos e a maioria eram cães sem raça definida. Também Silva et al. (2014), encontraram em seu estudo uma idade média de 10,1 anos (5-17). Referente à raça a maioria das cadelas atendidas pela pesquisa foi SRD (sem raça definida), o que correspondeu a 15 cadelas (80\%). Assim como o observado nas cadelas deste projeto de pesquisa, no Brasil, os tumores de mama acometem mais comumente cães de idade média a avançada, sem predisposição de raça (Daleck et al. 1998).

As informações referentes a vida reprodutiva e uso de progestágenos das pacientes atendidas pelo projeto nem sempre puderam ser respondidas de maneira adequada pelos proprietários. Da mesma forma como descrito por Bueno et al. (2008), a população local, e o próprio perfil de atendimento da clínica, tem como característica muito comum a adoção de animais de rua ou mesmo por doação de pessoas próximas aos proprietários, e com isso muitos deles não possuem informações anteriores sobre o animal. Portanto, as informações obtidas sobre o uso de progestágenos exógenos foi de que 6 cadelas (30\%) utilizaram uma ou mais doses de progestágeno durante a vida, 11 (55\%) não utilizaram, e $3(15 \%)$ os proprietários não souberam informar pois os animais eram adotados da rua já adultos.

Quanto ao número de nódulos 15 cadelas (75\%) apresentaram mais de um nódulo no momento do diagnóstico e apenas 5 (25\%), apresentavam nódulo único, corroborando com um estudo que documentou que $70 \%$ das fêmeas intactas tinham mais de um tumor mamário no momento do diagnóstico (Lana et al. 2007, Cassali et al. 2014).

Quanto ao envolvimento das glândulas mamárias, foi observado no presente estudo que as mamas mais acometidas por neoplasias foram a $\mathrm{M}_{3}$ e $\mathrm{M}_{4}$ As quartas e quintas glândulas mamárias são as mais acometidas já que apresentam maior quantidade tecidual e por estarem em uma região predisposta a traumatismos (Cirilo 2008, López et al. 2012).

Nos exames pré-operatórios a única alteração constatada na pesquisa foi leucocitose por neutrofilia em 9 cadelas (45\%). Este resultado encontra-se superior ao encontrado por Silva et al. (2014), que em seu estudo constataram leucocitose neutrofílica em $18,6 \%$ das pacientes. A leucocitose por neutrofilia verificada neste trabalho possivelmente reflete a condição inflamatória decorrente da neoplasia mamária, e também à ulceração presente em algumas pacientes (Childress 2012).

Quanto a classificação histológica $10 \%$ dos tumores pesquisados foram benignos e $90 \%$ malignos, resultado esse próximo ao encontrado por Oliveira et al. (2003), que em sua pesquisa observaram que em 71 cadelas com neoplasia mamária, $71,8 \%$ delas apresentaram neoplasias malignas e $28,2 \%$ neoplasias benignas. Entretanto, estes achados entram em desacordo com Fossum et al. (2008) e Feliciano et al. (2012) que citam que os tumores benignos representam cerca de $50 \%$ das neoplasias mamárias caninas. Tais divergências podem ser pelas próprias características da população atendida em nossa clínica escola, que em geral demora mais para buscar atendimento e com frequência suas cadelas apresentam neoplasias de grandes tamanhos e longo tempo de evolução. A maior incidência de neoplasias malignas em relação às benignas também foi observado no trabalho de Marchesi et al. (2010), onde as formas malignas da neoplasias corresponderam a $78,2 \%$ de todas as formas neoplásicas. Para os autores, esta maior ocorrência se justifica pelos pacientes terem sido atendidos por um cirurgião quando o estágio da doença neoplásica já estava avançado.

A presença de receptores hormonais nas neoplasias mamárias, como ER, PR, PRL-R e o EGF-R pode ser um indicativo da influência hormonal no desenvolvimento de neoplasias benignas ou malignas (Misdorp 2002). Ainda, as variações fisiológicas com influência hormonal nos tecidos mamários como a gestação psicológica, a gestação, ou o parto, que ocorrem normalmente depois de algum ciclo estral, não parecem influenciar na ocorrência da neoplasia mamária (Daleck et al. 1998, Lana et al. 2007). No presente trabalho, foi observado que 3 cadelas (15\%) encontravam-se em proestro e apresentavam hiperplasia mamária, porém, o ciclo estral dos animais não influenciou nos valores encontrados do marcador tumoral CA 15-3.

Durante o trabalho, uma das dificuldades foi a escassez de valores de referência fato também evidenciado por Marchesi et al. (2010) que realizaram a pesquisa com 57 amostras de soro e tecidos das fêmeas de cães com lesões mamárias neoplásicas e 24 amostras de soro de indivíduos clinicamente saudáveis para posterior comparação 
de resultados. Bicalho (2012) realizou uma pesquisa de dosagem do marcador CA 15-3 em cadelas hígidas através do ensaio imunoluminométrico por quimioluminescência e obteve valores médios de $0,4140 \pm 0,25 \mathrm{U} / \mathrm{mL}$ nas amostras concentradas duas vezes e $0,5170 \pm 0,25 \mathrm{U} / \mathrm{mL}$ nas amostras concentradas quatro vezes. No presente trabalho se pode observar que as cadelas com neoplasia mamária apresentaram valores maiores $(1,56 \pm 0,39 \mathrm{U} / \mathrm{mL})$, sem a necessidade de concentração da amostra. Ainda, a regressão dos valores de CA 15-3 após 10 dias da mastectomia, com queda da média de $1,56 \pm 0,39 \mathrm{U} / \mathrm{mL}$ pré-mastectomia para $0,66 \pm 0,27 \mathrm{U} / \mathrm{mL}$ pós-mastectomia mostrou-se importante para um futuro controle de recidivas, ou doença metastática. Este achado vem de encontro com Almeida et al. (2007), que em humanos relacionaram o aumento superior a $25 \%$ na concentração do CA 15-3 em pacientes com a progressão da doença em 80\% a $90 \%$ dos casos, e a diminuição em sua concentração está associada à regressão da doença em $70 \%$ a $80 \%$ dos casos.

Valencakova-Agyagosova et al. (2012) encontraram em seu trabalho com o método de radioimunoensaio valor médio de CA 15-3 em cadelas com tumor de 8,58 $\pm 1,27 \mathrm{U} / \mathrm{mL}$. Já Marchesi etal. (2010), com o método de quimiluminescência direta encontraram valores de $0.79 \pm 0.56 \mathrm{U} / \mathrm{mL}$. Valores diferentes dos encontrados na presente pesquisa, podendo ser explicado pelo diferente método utilizado.

Campos (2010) utilizou-se do ensaio ELISA para quantificar o marcador CA 15-3 em cadelas hígidas e portadoras de neoplasia mamária. As cadelas saudáveis apresentaram valores de $1,37 \pm 0,46 \mathrm{ng} / \mathrm{mL}$. As cadelas hígidas desse trabalho apresentavam valores de 0,19 $0,39 \mathrm{UI} / \mathrm{mL}$.

Como Marchesi et al. (2010) constataram em seus estudos, o uso da quimioluminescência e os kits utilizados na medicina humana podem ser promissores para a determinação dos níveis de CA 15-3 em cães, e os valores encontrados nesse estudo através da eletroquimioluminescência corroboram tal afirmação.

Mesmo com os valores significativos encontrados são necessários mais estudos sobre os marcadores tumorais em cães e também a busca da melhor técnica a ser utilizada para esta avaliação e de valores constantes que possam ser utilizados como referência.

Em relação aos resultados do histopatológico não foi verificada variação significativa sobre o tipo histológico e a elevação do marcador tumoral, e uma análise estatística mais apurada não foi realizada pela diferença dos grupos com 3 cadelas apenas com neoplasias benignas, e 17 cadelas com malignas. Visualmente observamos certa tendência de maior valor de CA 15-3 nas neoplasias benignas, porém não foi confirmada estatisticamente. Contudo, segundo Manuali et al. (2012) em sua pesquisa com 50 neoplasias mamárias malignas foi possível observar níveis mais significativos do marcador.

\section{CONCLUSÕES}

Através do método utilizado, observou-se diferença estatística nos valores do marcador CA 15-3 antes e depois da remoção cirúrgica da neoplasia nas cadelas, sugerindo seu possível uso como controle de crescimento tumoral pós-mastectomia individual.

Porém, há grande variabilidade dos resultados de acordo com os diferentes métodos de mensuração, faltando padronização dos valores de referência para cada método.

\section{REFERÊNCIAS}

Almeida J.R.C. 2006. Marcadores tumorais, p.61-72. In: Ibid. (Ed.), Farmacêuticos em Oncologia: uma nova realidade. Atheneu, São Paulo.

Almeida J.R.C., Pedrosa N.L., Leite J.B., Fleming T.R.P., Carvalho V.H. \& Cardoso A.A.A. 2007. Marcadores tumorais: revisão de literatura. Revta Bras. Cancerol. 53(3):305-316.

Araújo J.H.G. 2013. Principais marcadores tumorais utilizados na prática clínica: uma revisão bibliográfica. Monografia de Graduação. Disponível em <http://rei.biblioteca.ufpb.br/jspui/bitstream/123456789/566/1/ JHGA11072014.pdf> Acesso em 20 ago. 2016.

Bicalho S.R. 2012. Quantificação sérica do marcador tumoral CA 15.3 em cadelas hígidas por quimioluminescência. Dissertação de Mestrado. Disponível em <http://repositorio.unesp.br/handle/11449/89191> Acesso em 10 set. 2016.

Bueno A.V.J., Fávero C., Geron C.C., Takayama C.M., Giotto F. \& Campos F.L. 2008. Perfil da população canina e felina assistida pelo serviço de pronto atendimento da clínica escola veterinária (Cevet-Unicentro) no biênio 2007-2008. Salão de Extensão e Cultura, Guarapuava, PR. Disponível em <http://anais.unicentro.br/sec/isec/pdf/resumo_79.pdf> Acesso em 20 ago. 2016.

Campos L.C. 2010. Avaliação de marcadores tumorais séricos em cadelas com e sem metástase em câncer de mama. Dissertação de Mestrado. Disponível em <http://www.bibliotecadigital.ufmg.br/dspace/handle/1843/BUOS8M4HDH> Acesso em 23 out. 2016.

Capelozzi V.L. 2001. Entendendo o papel de marcadores biológicos no câncer de pulmão. J. Pneumol. 27(6):321-328. <http://dx.doi.org/10.1590/ S0102-35862001000600006>

Cassali G.D., Lavalle G.E., Ferreira E., Estrela-Lima A., De Nardi A.B., Ghever C., Sobral R.A., Amorim R.L., Oliveira L.O., Sueiro F.A.R., Beserra H.E.O., Bertagnolli A.C., Gamba C.O., Damasceno K.A., Campos C.B., Araujo M.R., Campos L.C., Monteiro L.N., Nunes F.C., Horta R.S., Reis D.C., Luvizotto M.C.R., Magalhães G.M., Raposo J.B., Ferreira A.M.R., Tanaka N.M., Grandi F., Ubukata R., Batschinski K., Terra E.M., Salvador R.C.L., Jark P.C., Delecrodi J.E.R., Nascimento N.A., Silva D.N., Silva L.P., Ferreira K.C.R.S., Frehse M.S., Di Santis G.W., Silva E.O., Guim T.N., Kerr B., Cintra P.P., Silva F.B.F., Leite J.S., Mello M.F.V., Ferreira M.L.G., Fukumasu H., Salgado B.S. \& Torres R. 2014. Consensus for the diagnosis, prognosis and treatment of canine mammary tumors. Braz. J. Vet. Pathol. 7(2):38-69.

Childress M.0.2012. Hematologic abnormalities in the small animal cancer patient. Vet. Clin. N. Am., Small Anim. Pract. 42(1):123-155. <http://dx.doi. org/10.1016/j.cvsm.2011.09.009><PMid:22285162>

Cirilo J.V. 2008. Tratamento quimioterápico das neoplasias mamárias em cadelas e gatas. Revta Inst. Ciênc. Saúde 26(3):325-327.

Daleck C.R., Franceschini P.H., Alessi A.C., Santana Á.E. \& Martins M.I.M. 1998. Aspectos clínico e cirúrgico do tumor mamário canino. Ciência Rural 28(1):95-100. <http://dx.doi.org/10.1590/S0103-84781998000100016>

De Nardi A.B., Rodaski S., Sousa R.S., Costa T.A., Macedo T.R., Rodigheri S.M., Rios A. \& Piekarz C.H. 2002. Prevalência de neoplasias e modalidades de tratamentos em cães atendidos no Hospital Veterinário da Universidade Federal do Paraná. Arch. Vet. Sci. 7(2):15-26. <http://dx.doi.org/10.5380/ avs.v7i2.3977>

Eisenberg A.L.A. \& Koifman S. 2001. Câncer de mama: marcadores tumorais (revisão de literatura). Revta Bras. Cancerol. 47(4):377-388.

Feliciano M.A.R., João C.F., Cardilli D.J., Crivelar R.M. \& Vicente W.R.R. 2012. Neoplasia mamária em cadelas: revisão de literatura. Revta Cient. Eletrôn. Med. Vet. 9(18):15-30.

Fonseca C.S. \& Daleck C.R. 2000. Neoplasias mamarias em cadelas: influência hormonal e efeitos da ovário: histerectomia como terapia adjuvante. Ciência Rural 30(4):731-735. <http://dx.doi.org/10.1590/S010384782000000400030> 
Fossum T.W., Hedlund C.S., Hulse D.A. \& Johnson A.L., Seim III H.B., Willard M.D. \& Carroll G.L. 2008. Cirurgia de Pequenos Animais. 2aa ed. Roca, São Paulo. 1390p.

Garrido E. 2011. Determinação dos valores plasmáticos de osteopontina em cães com tumores mamários metastáticos ou não. Correlações clínicas e anatomopatológicas. Dissertação de Mestrado. Disponível em <http:// repositorio.unesp.br/handle/11449/95960> Acesso em 15 abr. 2016.

Geraghty J.G., Coveney E.C., Sherry F., O’Higgins N.J. \& Duffy M.J. 1992. CA 15-3 in patients with locoregional and metastatic breast carcinoma. Cancer 70(12):831834. <http://dx.doi.org/10.1002/1097-0142(19921215)70:12<2831::AIDCNCR2820701218>3.0.C0;2-8><PMid:1451063>

Lana S.E., Ruttman G.R. \& Withrow S.J. 2007. Tumors of the mammary gland, p. 619-636. In: Withrow S.J. \& Vail D.M (Eds), Withrow and Macewen's Small Animal Clinical Oncology. 4th ed. Elsevier, St Louis. <http://dx.doi. org/10.1016/B978-072160558-6.50029-0>.

López C.N., Ramón G N., Sánchez M J.I. \& de Santiago G J. 2012. Metástasis óseas múltiples de cáncer de mama. Papel del CA 15.3 y respuesta a la hormonioterapia. Revta Chil. Obstet. Ginecol. 77(4):291-295. <http:// dx.doi.org/10.4067/S0717-75262012000400009>

Manuali E., De Giuseppe A., Feliziani F., Forti K., Casciari C., Marchesi M. C., Pacifico E., Pawlowski K. M., Majchrzak K. \& Król M. 2012. CA 15-3 cell lines and tissue expression in canine mamary câncer and correlation between serum levels and tumor histological grade. BMC Vet. Res. 8(86):1-10. <http://dx.doi.org/10.1186/1746-6148-8-86>

Marchesi M.C., Manuali E., Pacífico E., Ferri C., Romagnoli M., Mangili V. \& Fruganti G. 2010. Cancer antigen 15/3: possible diagnostic use in veterinary clinical oncology: preliminary study. Vet. Res. Commun. 34(Suppl.1):103-106. <http://dx.doi.org/10.1007/s11259-010-9392-3> <PMid:20432064>

Mattos L.L., Machado L.N., Sugiyama M.M., Bozzetti R.M. \& Pinhal M.A.S. 2005. Tecnologia aplicada na detecção de marcadores tumorais. Arq. Med. ABC 30(1):19-25.

Misdorp W. 2002. Tumors of the mammary gland, p.575-606. In: Meuten D.J. (Ed.), Tumors in Domestic Animals. 4th ed. Iowa State Press, Iowa.
Oliveira G.G. \& Fonseca C.A. 2011. Uso de marcadores tumorais no diagnóstico e acompanhamento do tratamento do câncer. Revta Eletrôn. Farmácia 8(2):60-74.

Oliveira L.O., Oliveira R.T., Loretti A.P., Rodrigues R. \& Driemeier D. 2003. Aspectos epidemiológicos da neoplasia mamária canina. Acta Scient. Vet. 31(2):105-110.

Rodaski S. \& Piekars C.H. 2009. Biologia do câncer, p.24-49. In: Daleck C.R., De Nardi A.B. \& Rodaski S. (Eds), Oncologia em Cães e Gatos. Roca, São Paulo.

Sakamoto S.S. 2011. Identificação de elementos traços em tumores de mama de cadelas e sua correlação com histopatologia e prognóstico de vida. Dissertação de Mestrado. Disponível em <http://repositorio.unesp.br/ handle/11449/94699> Acesso em 15 ago. 2016.

Silva A.H.C., Silva D.M., Ribas C.R., Dittrich R.L., Dornbusch P.T. \& Guérios S.D. 2014. Alterações no hemograma de cadelas com neoplasia mamária. Ciênc. Anim. Bras. 15(1):87-92.<http://dx.doi.org/10.5216/cab.v15i1.20144>

Silveira L.A. 2005. Câncer Ginecológico: Diagnóstico e Tratamento. UFSC, Florianópolis. 382p.

Souza J.V. 2002. Marcadores mucinosos associados a câncer. Revta Amrigs, Assoc. Méd. RS 46(1/2):70-83.

Valencakova-Agyagosova A., Frischova Z., Sevcikova Z., Hajurka J., Lepej J., Szakallova I., Kredatusova G., Nagy V. \& Ledecky V.2012. Determination of carcinoembryonic antigen and cancer antigen (CA 15-3) in bitches with tumours on mammary gland: preliminary report. Vet. Comp. Oncol. 12(3):205-214. <http://dx.doi.org/10.1111/j.1476-5829.2012.00353. $\mathrm{x}><$ PMid:22947252>

Withrow S.J. \& Macewen E.G. 2007. Small Animal Clinical Oncology. 4th ed. Elsevier, St Louis. 846p.

Zuccari D.A.P.C., Castro R., Gavioli A.F., Mancini U.M., Tajara E.H., Frade C.S., Pivaro L.R., Carmona-Raphe J., Terzian A.C.B., Ruiz C.M., Bertollo E.M.G. \& Pavarino-Bertelli É.C. 2009. The maspin expression in canine mammary tumors: an immunohistochemical and molecular study. Pesq. Vet. Bras. 29(2):167-173. <http://dx.doi.org/10.1590/S0100-736X2009000200015> 